\title{
A study of histopathological spectrum of non-malignant breast lesions
}

\author{
Maru A. M. ${ }^{1}$, Menapara C. B. ${ }^{2}$ \\ ${ }^{1}$ Dr. Alpesh M. Maru, Assistant Professors, ${ }^{2}$ Dr. Chiragkumar B. Menapara, Assistant Professors; both authors are \\ affiliated with Department of Pathology, GMERS Medical College, Junagadh, Gujarat, India.
}

Corresponding Author: Dr. Chiragkumar B. Menapara. Assistant Professors; both authors are affiliated with Department of Pathology, GMERS Medical College, Junagadh, Gujarat, India, E-mail: drmaru28@gmail.com

\begin{abstract}
Background: Breast Lesions include a variety of Non-malignant and malignant lesions sometimes producing diagnostic difficulty for both Clinicians as well as Pathologists. In certain cases, histopathological examination, particularly microscopy is the only way to reach to the final diagnosis, so our present study is undertaken to know about the Spectrum of variousnon-malignant breast lesions and Frequency of their occurrence. Materials \& Methods: The present study is carried out in the Department of Pathology, GMERS Medical College-Junagadh from September 2015 to August 2018. Excisional and incisional breast biopsies as well as lumpectomy specimens from surgical department have been evaluated both grossly and microscopically for this present study. Results: Out of 200 cases studied during last 3 years, 155 cases belong to non-malignant (non-neoplastic and benign) lesions while 45 cases belong to malignantlesions (breast cancers). The incidence of non-malignant breast lesions is found to be $77.50 \%$ of all breast lesions. Out of all non-malignant breast lesions, Fibroadenoma is found to be the commonest one (Total 75 cases, 48.39\%) followed by Fibrocystic Disease found in 15 cases $(9.68 \%)$. Conclusion: Non-malignant breast lesions include a variety of inflammatory lesions, benign tumors and tumor like conditions. Histopathological evaluation becomes necessary for such cases and plays a pivot role in their final diagnosis.
\end{abstract}

Key words: Non-malignant, Spectrum, Frequency Distribution

\section{Introduction}

Lump or Mass in the breast is an issue of worry or anxiety particularly for female patients of all age groups and sometimes produces diagnostic difficulty for both Clinicians as well as Pathologists. Benign breast Diseases is defined as any non-malignant breast condition and encompasses a wide range of clinical and pathologic disorders [1]. It is one of the most common diseases in the females of any society [2].

Though majority complains are neglected [3]. In order to provide relief to the patients from anxiety, timely, precise and accurate diagnosis is must. Accuracy and Precision save a patient's life in breast cancers and in cases of non-malignant lesions, they avoid unnecessary mutilating radical surgery and preserve patient's breast. In other words one can say that to prevent unnecessary loss of breast, perfect diagnosis of non-malignant lesions is of utmost importance. Non-malignant lesions include both non-neoplastic and neoplastic lesions. Histopathological examination is now considered a gold

Manuscript received: $10^{\text {th }}$ October 2018

Reviewed: $20^{\text {th }}$ October 2018

Author Corrected: $26^{\text {th }}$ October 2018

Accepted for Publication: $31^{\text {st }}$ October 2018 standard approach to the diagnosis of breast lump [4]. They also include tumor like conditions e.g. Hamartomas. The incidence of benign breast lesions begins toriseduring the second decades of life and peaks in the fourth and fifth decades [5,6]. So in our present study, we have used the more accurate term "Nonmalignant" instead of the term "Benign". Main purpose of this study is to know about the Histopathological Spectrum of variousnon-malignant breast lesions and Frequency of their occurrence.

\section{Materials \& Methods}

The present Prospective study is carried out in the Department of Pathology, GMERS Medical CollegeJunagadh from September 2015 to August 2018 for a period of 3 years. It includes a total number of 155 cases out of 200 cases of various breast lesions.

Surgical Pathology specimens in terms of Incisional Biopsies, Excisional Biopsies and Lumpectomies have been received from surgical department directly with adequate and relevant clinical details in a specific performa of histopathology laboratory requisition form. 


\section{Original Research Article}

After fixation in $10 \%$ formalin, gross examination and dissection of specimens are done in order to obtain necessary tissue bits. These bits are further processed, embedded in paraffin wax and microtomy is done to obtain thin tissue sections that can be examined further under microscope after staining with routine $\mathrm{H}$ \& $\mathrm{E}$ method. On the basis of both gross and microscopic findings, final diagnosis is given in the form of histopathology report having a specific Performa.All data are analyzed by simple statistical method with Statistical Package for the Social Sciences (SPSS) software, $\mathrm{p}$ value $<0.05$ is considered as statistically significant.

\section{Inclusion Criteria}

1. All female patients with Age range: 10 years and above.

2. Excision biopsy specimens which proved benign on FNAC

\section{Exclusion Criteria}

1. MRM specimen which is malignant clinically or on FNAC.

2. Age less than 10 years.

\section{Results}

During last three years from September 2015 to August 2018, a total number of 200 cases of breast lesions have been received and out of them 155 cases are of non-malignant lesions. The incidence of non-malignant lesions in our present study is found to be $77.50 \%$. Out of these non-malignant lesions, Fibroadenoma is found to be the commonest one (Total 75 cases, 48.39\%) followed by Fibrocystic Disease in frequency (15 cases, 9.68\%). Table no. 1 depicted entire spectrum and frequency of occurrence of various non-malignant breast lesions on histopathological basis.

Table No.-1: Spectrum and frequency of occurrence of various non-malignant breast lesions.

\begin{tabular}{|c|c|c|c|}
\hline Sr. No. & Histopathological Diagnosis & Total No. of Cases & Percentage (\%) \\
\hline 1 & Fibroadenoma & 75 & 48.39 \\
\hline 2 & Fibrocystic Disease & 10 & 9.68 \\
\hline 3 & Fibroadenosis & 10 & 6.45 \\
\hline 4 & Apocrine Adenosis & 09 & 5.81 \\
\hline 5 & Nonspecific Mastitis & 07 & 4.52 \\
\hline 6 & Gynecomastia & 06 & 3.87 \\
\hline 7 & Granulomatous Mastitis & 05 & 3.23 \\
\hline 8 & Benign Phylloids Tumor & 05 & 3.23 \\
\hline 9 & Tubular Adenoma & 05 & 1.93 \\
\hline 10 & Lactating Adenoma & 03 & 1.93 \\
\hline 11 & Breast Abscess & 03 & 0.64 \\
\hline 12 & Breast Tuberculosis & 01 & 0.64 \\
\hline 13 & Intraductal Papilloma & $\mathbf{1 5 5}$ & $\mathbf{1 0 0}$ \\
\hline 14 & Antibioma & 01 & \\
\hline $\mathbf{1 5}$ & Total & & 05 \\
\hline
\end{tabular}

Fibroadenoma was most common benign lesion with $48.39 \%$ incidence. They prevalent in age group of $15-25$ years with average being 20 years.

Fibrocystic disease was next common non malignant lesion with $9.68 \%$ incidence with age range 30-45 years with average being 37 years. The youngest patient was 15 years old with having diagnosis of fibroadenoma.

Presenting complains of patients were mostly lump (55\%) alone followed by Lump with pain (30\%). Few are having complain of only pain \& discharge. 


\section{Original Research Article}

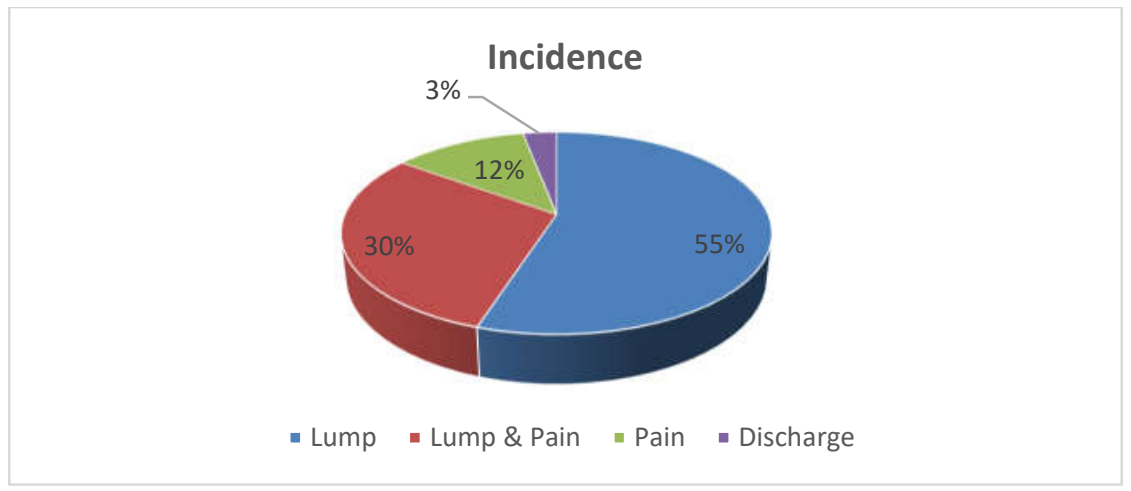

Figure No. 1: spectrum and frequency of occurrence of various non-malignant breast lesions.

Out of 155 non - malignant lesions of breast that we had received, 90 patients had a right sided lesion and 55 left sided lesion while bilateral lesion was present in 10 patients. FNAC was carried out in 137 cases, out of which the results were confirmed to be similar to the histopathologic examinations in 126 cases. Ultrasound was carried out in 18 patients where FNAC results were acellular, inconclusive or could not be relied on due to in sufficient material and inpatients with nonpalpable lesions.
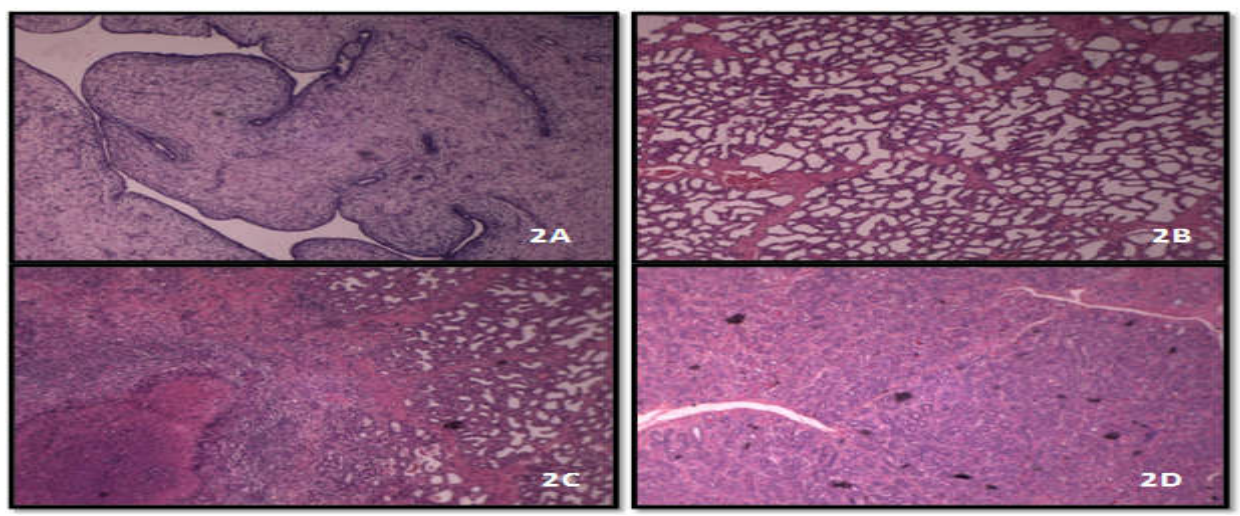

Figure No. 2 shows microscopic pictures of various non-malignant breast lesions (H \& E X 100) 2 A: Microscopic Picture of Benign Phylloid tumor; 2B: Microscopic Picture of Lactating adenoma 2 C: Microscopic Picture of TB Mastitis; 2D Microscopic Picture of Fibroadenosis

Figure no. 2 shows microscopic pictures of various non-malignant breast lesions. Figure 2A shows picture of Benign Phylloids Tumor having a leaf like architecture or growth pattern due to over growth of stromal component. Figure 2B shows Lactating Adenoma having dilated lactating ducts lined by a single layer of epithelium. Figure $2 \mathrm{C}$ shows Tuberculous Mastitis having a large central area of Caseous Necrosis surrounded by Epitheloid Macrophages, Langhan's Giant Cells and chronic inflammatory cells. Figure 2D shows picture of Fibroadenosis having proliferation of uniform round to oval glandular components admixed with fibrous or stromal tissue. Ratio between glands and stroma is increased in each breast lobule.

Out of 155 cases, only 7 cases are male (4.52\%) and rest of 148 cases are females (95.48\%). Majority of the cases belong to age group of 21-30 years (total 61 cases, 39.35\%) followed by age group of 11-20 years (total 38 cases, 24.52\%). Nonmalignant lesions are seen mostly in younger females particularly those who are in their reproductive period of life. Such lesions become uncommon after menopause. The commonest non-malignant breast lesion in males is Gynecomastia that is seen in all 7 cases and affects all age groups.

\section{Discussion}

Inflammatory diseases of the breast are uncommon, accounting for less than $1 \%$ of women with breast symptoms. Women usually present with an erythematous swollen painful breast. "Inflammatory breast cancer" mimics inflammation by obstructing dermal vasculature with tumor emboli, resulting in an enlarged erythematous breast, and should always be 


\section{Original Research Article}

suspected in a non lactating woman with the clinical appearance of mastitis. Inflammatory lesions includes acute mastitis, periductal mastitis, mammary duct ectasia, Fat necrosis, lymphocytic mastopathy and granulomatous mastitis. Lesions have been divided into three groups, according to the subsequent risk of developing breast cancer: (1) no proliferative breast changes, (2) proliferative breast disease without atypia and (3) proliferative breast disease with atypia. Non proliferative lesions mainly include Fibrocystic disease of breast which clinically present with lumpy-bumpy breast on palpation. It includes three components such as Cyst, Fibrosis and adenosis. Proliferative lesion without atypia includes Epithelial hyperplasia, sclerosing adenosis, complex sclerosing lesion, papillomas. proliferative breast disease with atypia. Entity includes atypical ductal hyperplasia, atypical lobular hyperplasia. The breast specific biphasic stromal tumors fibroadenoma and phyllodes tumor arise from intralobular stroma. This specialized stroma may elaborate growth factors for epithelial cells, resulting in the proliferation of the non-neoplastic epithelial component of these tumors.

Fibroadenoma is the most common benign tumor of the female breast. Most occur in women in their 20s and 30s, and they are frequently multiple and bilateral. Young women usually present with a palpable mass and older women with a mammographic density or mammographic calcifications. The epithelium of the fibroadenoma is hormonally responsive, and an increase in size due to lactational changes during pregnancy, which may be complicated by infarction and inflammation, can mimic carcinoma. Phyllodes tumors can occur at any age, most present in the sixth decade, 10 to 20 years later than the peak age for fibroadenomas. The majority are detected as palpable masses, but a few are found by mammography. The tumors vary in size from a few centimeters to massive lesions involving the entire breast.

The larger lesions often have bulbous protrusions ("leaflike") due to the presence of nodules of proliferating stroma covered by epithelium. In our present study, 155 cases (77.50\%) out of total 200 cases of breast lesion are non-malignant and 45 cases (22.50\%) are malignant. In a study done by Kulkarni Sangeeta et al[7], out of 176 cases, non-malignant breast lesions constituted $80.7 \%$ while malignant lesions constituted $19.3 \%$. Malik et al[8] reported non-malignant lesions in $72.97 \%$ and malignant lesions in $27.03 \%$.Pudale $\mathrm{S}$ et al [9] reported non-malignant lesions in $71.15 \%$ and malignant lesions in $28.85 \%$. So we can say that incidence of both non-malignant as well as malignant breast lesions is comparable in all studies.

Total 155 cases have been included in our present study, out of them 148 patients $(95.48 \%)$ are female \& 7 patients (4.52\%) are male. In a similar study done by Kulkarni Sangeeta et al[7], out of 176 cases, 171 were females (97.16\%) and five were males (2.84\%). In a study done by Malik et al[8], 94.52\% patients were females \& $5.48 \%$ patients were males. In a study done by Pudale S et al [9], $97.78 \%$ patients were females \& $2.22 \%$ patients were males so, female: male ratio or gender ratio remains more or less similar in all studies.

In our present study, Fibroadenoma is found to be the commonest one among all non-malignant breast lesions ( 75 cases, 48.39\%) followed by Fibrocystic Disease (15 cases, 9.68\%). Histopathological Spectrum of our present study is compared with that of other similar studies in Table no. 2.

\section{Table No.-2: Comparison of Histopathological Spectrum of Non-malignant Breast Lesions}

\begin{tabular}{|c|c|c|c|c|c|c|c|c|}
\hline$\underset{\dot{n}}{\stackrel{\dot{Z}}{\dot{n}}}$ & 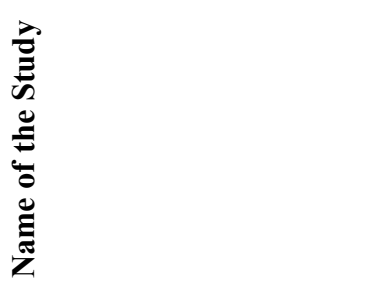 & 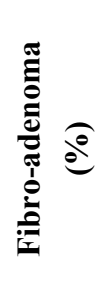 & 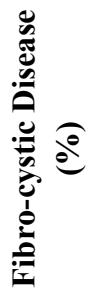 & 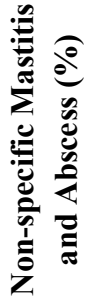 & 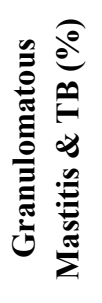 & 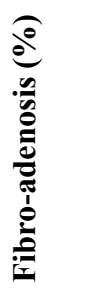 & 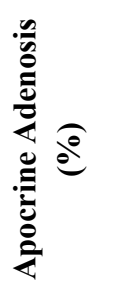 & 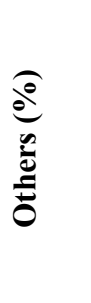 \\
\hline 1 & Present Study & 48.39 & 9.68 & 7.74 & 5.81 & 6.45 & 6.45 & 15.48 \\
\hline 2 & Kulkarni Sangeeta et al[7] & 62.32 & 11.59 & 4.35 & 1.45 & -- & -- & 20.29 \\
\hline 3 & Pudale S et al [9] & 40.00 & 32.87 & 3.88 & 3.89 & -- & -- & 19.36 \\
\hline 4 & Vijayalakshmi M et al[10] & 70.00 & 20.00 & -- & -- & -- & -- & 10.00 \\
\hline 5 & Khanna et al [11] & 72.00 & 10.00 & -- & -- & -- & -- & 18.00 \\
\hline 6 & Raja \& Narayan[12] & 49.93 & 40.53 & 5.58 & 1.17 & -- & -- & 2.79 \\
\hline 7 & Oluwale \& Freeman[13] & 48.51 & 23.56 & 5.63 & 1.88 & -- & -- & 20.42 \\
\hline 8 & Haqque et al [14] & 52.88 & 22.12 & 7.69 & 1.93 & -- & -- & 15.38 \\
\hline
\end{tabular}

Pathology Update: Tropical Journal of Pathology \& Microbiology Available online at: www.pathologyreview.in 445 | P a g e 


\section{Original Research Article}

From details mentioned above in Table no. 2, it is obvious that histopathological spectrum or pattern of non-malignant breast lesions remains more or less similar everywhere with some minor exceptions \& Fibroadenoma being commonest among all non-malignant breast lesion followed by others.

In our present study, majority of cases belong to $3^{\text {rd }}$ decade of life (21-30 years of age) followed by $2^{\text {nd }}$ decade (11-20 years of age). Certain non-malignant lesions like Gynecomastia, Breast Abscess, Tuberculosis, etc. can occur in any age group and show no definite association with patient's age, while certain lesions like Tubular Adenoma, Lactating Adenoma, Benign Phylloids Tumor, Fibrocystic Disease, etc. have some association with patient's age.

In our present study, we have included total 5 cases of Tubular Adenoma and out of them 4 cases belong to age group of 11-20 years ( $2^{\text {nd }}$ decade). Tubular Adenomas are pure epithelial adenomas seen at somewhat younger age as compared to other non-malignant lesions and uncommon after $3^{\text {rd }}$ decade of life. Other studies like those done by O'Hara and Page [15] and James et al [16] also found comparable results.

Benign Phylloids Tumor occurs in a slightly older age group (41-50 years or $5^{\text {th }}$ decade). Our present study and other similar studies like those done by Choudhary \& Khanna [17] and by Pudale S et al [9]observed comparable results.

Lactating Adenomas are usually common during reproductive period of life and seen during 21-30 years commonly. Clinical History of Pregnancy and Lactation is necessary in these cases to give the final diagnosis. Our present study includes 5 such cases and findings are comparable with other similar studies like those done by Pudale S et al [9].

\section{Conclusion}

Non-malignant breast lesions include a variety of inflammatory lesions, benign tumors and tumor like conditions. Fibroadenoma was most common benign lesion with $48.39 \%$ incidence with age range isof $15-25$ followed by Fibrocystic disease with $9.68 \%$ incidence with age range 30-45 years. Most common presenting symptoms for non malignant lesions are lump. Thus breast self-examination and education to females is very importantincasesofbenignbreasttumors. Histopathologica 1 evaluation becomes necessary for such cases and plays a pivot role in their final diagnosis. It also becomes helpful to surgeons for making decision of further operative management of the patient.

\section{Contribution from the Author}

- Dr. Alpesh M. Maru: Data collection, analysis and preparation of manuscript.

- Dr. Chiragkumar Menpara: Analysis and preparation of manuscript \& critical revision.

Findings: Nil; Conflict of Interest: None initiated Permission from IRB: Yes

\section{References}

1. Rangabashyam N, Gnanaprakasam D, Krishnaraj B, et al. Spectrum of benign breast lesions in Madras. J R Coll Surg Edinb. 1983 Nov; 28(6):369-73.

2. Guray M, Sahin AA. Benign breast diseases: classification, diagnosis, and management. Oncologist. 2006 May;11(5):435-49.DOI:10.1634/ theoncologist. $11-5-435$
3. Srivatsava A, Dhar A. Benign breast disease: a neglected entity. Recent Adv Surg 2006;10:175-201.

4. Hughes LE, Mansel RE, Webster DJT. The approach to diagnosis and assessment of benign breast lumps benign disorders and diseases of the breast concepts and clinical management, $2^{\text {nd }}$ edition. London: WB Saunders; 2005:35.

5. Kelsey JL, Gammon MD. Epidemiology of breast cancer. Epidemiol Rev. 1990;12:228-40.

6. Cole P, Mark Elwood J, Kaplan SD. Incidence rates and risk factors of benign breast neoplasms. Am J Epidemiol. 1978 Aug;108(2):112-20.

7. Kulkarni Sangeeta et al, Histopathological spectrum of breast lesions with reference touncommon cases. J Obstet Gynecol India 2009;59(5): 444-452.

8. Malik R, Bharadwaj VK. Breast lesions in young females--a 20-year study for significance of early recognition. Indian J Pathol Microbiol. 2003 Oct;46 (4): 559-62.

9. Pudale $\mathrm{S}$ et al. A histopathological study of nonmalignant breast lesions. Int J Res Med Sci. 2015 Oct; 3 (10): 2672-2676.

10. Vijayalakshmi $M$ et al. Prevalence of Benign Breast Disease and Risk of Malignancy in Benign Breast Diseases. IOSR Journal of Dental \&Medical Sciences 2016;15(8):32-36. 


\section{Original Research Article}

11. Khanna U: Benign Breast Lump. A study of 250 15. O'Hara MF, Page DL. Adenomas of the breast and cases. Maharashtra. Med. Jr. 1985;34: 397.

12. Raja GC, Narayan Singh V. Benign Breast Disease in West Indian Population. Brit M J. 1985; 72:17-18.

13. Oluwole SF, Freeman HP. Analysis of benign breast lesions in blacks. Am J Surg. 1979 Jun;137(6):786-9.

14. Haqque et al. Breast Lesions. A clinic-pathological study of 200 cases of Breast lumps. Ind J Surg. 1980; ectopic breast under lactational influences. Hum Pathol. 1985 Jul;16(7):707-12.

16. James K, Bridger J, Anthony PP. Breast tumour of pregnancy ('lactating' adenoma). J Pathol. 1988 Sep; 156(1): 37-44. DOI:10.1002/path.1711560109

17. Choudhary B, Khanna V. Cystosarcoma Phyllodes: A Report of Six Cases. Ind J Surg. 1980; 402-407.

\section{How to cite this article?}

Maru A. M, Menapara C. B. A study of histopathological spectrum of non-malignant breast lesions. Trop J Path Micro 2018; 4(6):442-447.doi:10.17511/jopm.2018.i06.05. 